\title{
Risk factors for stillbirth and beliefs: findings from a pilot near miss questionnaire study in Somaliland focusing the mother-baby dyad
}

\begin{abstract}
Background: Somalia is one of 13 countries in Africa with stillbirth rates of more than 30 per 1000 total birth. To our knowledge no study in Somaliland has focused on the mother-baby dyad regarding risk factors for stillbirth. The objective of this study was to identify frequency, causes and beliefs for stillbirth in mothers with life threatening conditions as a pilot for a potential nationwide near-miss study with full coverage in the Somaliland health care system.
\end{abstract}

Method: A prospective cross sectional study using the WHO near-miss questionnaire in a tertiary level hospital with 1.385 deliveries during a five months period in 2015 .

Results: Out of 138 near miss and death events $22 \%(n=30)$ had a stillbirth. Seventyseven percent $(77 \%)$ of the mothers $(n=23)$ with stillborn babies survived and $23 \%$ died $(n=7)$. They were diagnosed with life threatening conditions, possible to prevent, on arrival at the tertiary hospital. None of them developed the maternal complication/s during the hospital stay. Cesarean sections (43\%) were performed within three hours after arrival. Beliefs regarding the stillbirth for the near miss women were that holding the baby born death helps them cope with the loss (74\%) and that religious believes helps them cope faster with the loss (91\%).

Conclusion and clinical implications: The near miss women, their families, TBAs and SBAs might need better information of what causes a stillbirth, how they could prevent it and about the near miss women's beliefs surrounding stillbirth to enable them to communicate this to pregnant women and prevent delay in admission to the tertiary level hospital. Furthermore, this pilot study suggest that the "Near Miss Questionnaire" could be used in low-and middle income settings to detect a full picture of the situation with stillbirth in a country.

Keywords: maternal near miss, stillbirth, maternal death, health care system, Somalia
Volume 5 Issue 3 - 2017

\author{
Jonah Kiruja,' Fatumo Osman, ${ }^{2}$ Jama Ali \\ Egal,' Marie Klingberg-Allvin, ${ }^{3}$ Mari-Cristin \\ Malm, ${ }^{4}$ Kerstin Erlandsson ${ }^{5}$ \\ 'Faculty of Nursing and Midwifery, Hargeisa University, \\ Somaliland \\ ${ }^{2}$ Health and Social Studies, Dalarna University, Sweden \\ ${ }^{3}$ Health and Social Studies, Dalarna University, Sweden \\ ${ }^{4}$ Health and Social Studies, Dalarna University, Sweden \\ ${ }^{5}$ Health and Social Studies, Dalarna University, Sweden
}

Correspondence: Kerstin Erlandsson, Ph.D, Senior Lecturer, Associate Professor, School of Education, Health and Social Studies, Dalarna University, Falun, Sweden, Tel +46 701808207, Email ker@du.se

Received: May 25, 2017 | Published: June 28, 2017

\section{Introduction}

Since 1991 when the civil war ended, a formerly British Somaliland Protectorate, is a self-declared country located at the Horn of Africa. The population is approximately 3.5 million with most of the population resident in rural areas. It is estimated that, $80 \%$ of deliveries are being conducted by Traditional Birth Attendants (TBAs) at homes while $20 \%$ of deliveries are performed in health facilities by Skilled Birth Attendants (SBAs). ${ }^{1}$ Somalia has one of the highest maternal (732/100 000) and child (137/1000) mortality ratios worldwide. ${ }^{2,3}$ The government of Somaliland has since 1991 stepwise re-established the health care and education system. The state systems are still to be considered fragile and the traditional family structures are strong particularly in rural areas. Great improvements has been made in re-establishing midwifery, antenatal care and re-building hospitals for referral of complicated cases from $\mathrm{MCHs}$, however maternal and child mortality ratios remains high. ${ }^{4}$ The stillbirth ratio in Somaliland particularly is unknown, however orally in society stillbirths are expressed as being a major problem. The estimate of stillbirth in Somaliland, Puntland and South Central region allinclusive, and recognized as Somalia, is 35.5 per 1000 births. Somalia is one of 13 countries in Africa with stillbirth rates of more than 30 per 1000 total birth. ${ }^{5}$
Population based studies worldwide has recognized a wide range of factors, from health system dynamics to social determinants of health and underlying health conditions that, contribute to the pregnancy outcome of stillbirth. The highest mortality risk for mothers and their babies is on the day of birth, and most of these deaths are preventable. ${ }^{6}$ The large burden of deaths that occurs in low-income countries, particularly in sub-Saharan Africa and South Asia, is due to their young population and high fertility. ${ }^{7}$ The first paper of the Lancet Series on ending preventable stillbirths reviews progress in essential areas, identified in the 2011 call to action for stillbirth prevention. Antenatal conditions, such as hypertension and anemia, have been found to be strong risk factors for intrapartum complications. ${ }^{6-9}$ Therefore Antenatal Care (ANC) has been identified as a main contributing factor for successful outcome of pregnancies. Early initiation of ANC and proper ANC is thought to reduce the risk of many adverse birth outcomes. However, when it comes to stillbirth early ANC compared to ANC initiation in the third trimester might not make any difference in low-resource settings. ${ }^{10}$ It has been suggested from WHO that from 2015 an onwards the mother-baby dyad must be applied. ${ }^{11}$ A healthy mother is more unlikely to get a stillborn. ${ }^{11,12}$ Hence, the mother-baby dyad approach is the one applied by WHO to end preventable stillbirths particularly in low resource settings before $2030 .{ }^{12}$ The mother-baby dyad approach needs to be applied in tertiary 
level hospitals in low-resource settings to monitor frequency, causes and beliefs of stillbirth in women with life threatening conditions. ${ }^{13}$ Furthermore, the maternal health literature often suggests that women's health outcomes will be satisfactory if they can access skilled attendance at delivery and emergency obstetric care when pregnancy and delivery complications occur. ${ }^{14}$ To our knowledge no study in Somaliland has focused on the mother-baby dyad regarding risk factors for stillbirth. In order to close this gap the objective of this study was to identify frequency, causes and beliefs for stillbirth in mothers with life threatening conditions as a pilot for a potential nationwide near-miss study with full coverage in the Somaliland health care system.

\section{Methods}

\section{Setting}

The tertiary level hospital, where this study was conducted in 2015 , is located in the largest city in Somaliland with an estimation of 1.5 million inhabitants. Women of child bearing age in the region were about 344000 and were served by a total of $38 \mathrm{MCHs} .{ }^{1}$ The hospital handled about 2940 deliveries in 2014. In the obstetric department there were a labour ward, an Intensive Care Unit (ICU), an operating theatre and two gynecology wards. In these wards pregnant and laboring women, gynecological- and maternal near miss cases were cared for. Five senior obstetricians/gynecologists, five junior medical doctors, nine diploma midwives, four community midwives and four nurses staffed the obstetric department. In the ICU, vaso-active drugs and ventilation were available. Blood for transfusions was supplied through the hospitals blood bank unit staffed with eight laboratory technicians. Five doctors staffed the unit.

\section{Study design and study population}

This study was a prospective cross sectional study performed over a period of 5 months in 2015 . The study population consisted of all maternal near miss cases admitted and maternal deaths registered during the study period. Inclusion criteria were women giving birth to a stillborn baby, surviving or ad mortem in the life threatening condition. Excluded were women who delivered a live born baby. A maternal death was defined as "The death of a woman while pregnant or within 42days of termination of pregnancy from any cause". ${ }^{14}$ The University of Hargeisa Research Ethics Committee (ref UOH/RES/ ETH014) first obtained ethical clearance. The Ministry of Health then gave ethical and research approval to conduct the study at the tertiary level hospital. In addition, the hospital administration was briefed about the purpose of the study and they accepted the study to be conducted at the facility.

\section{Instrument}

A standardized instrument, the Near-Miss and quality of care questionnaire, ${ }^{13}$ was used. A maternal near miss was defined as "a woman who nearly died but survived a life-threatening complication that occurred during pregnancy, childbirth or within 42days of termination of pregnancy. ${ }^{15}$ The instrument provided information on maternal health outcomes (maternal near miss, maternal deaths), demographic and reproductive risk factors. The structured form contained the following sections: screening questions, maternal information, underlying causes and contributing/associated factors. This study focuses frequency, causes and beliefs for stillbirth in mothers with life threatening conditions who gave birth to a stillborn baby. Self/family referral means the women and her family without TBA or SBA suggestions bypassed the MCH's and arrived to the tertiary level hospital by their own initiative. Regarding caesarean section, the father of the woman and the woman's husband have to sign prior to a caesarean section. In addition to the Near-Miss and quality of care questionnaire ${ }^{13}$ five questions with closed alternatives (yes/no) were posted regarding beliefs surrounding stillbirth to the 23 near miss cases who survived the life threatening condition. The questions were "Holding the baby born dead helps me cope with the loss", "Religious belief helps me cope faster with the loss of the baby", "I was aware about the cause of the stillbirth and when it occurred", "After a stillbirth the mother's womb is left with diseases which will cause complications in the next pregnancy" and "My husband is well informed about how to support me after the loss of the baby".

\section{Data collection}

The "Maternal Near Miss and Quality of Care Questionnaire" was distributed in the tertiary level hospital in Somaliland. The data collectors were trained by the investigators on how to fill out the questionnaire. Cases were identified on a daily basis by the data collectors working as medical staff (nurses, midwives, and doctors) and through daily visits to the labour ward, Intensive Care Unit (ICU), operating theatre and two gynecology wards for the principal investigator (JK). The questionnaire was embedded in the patient file. The data collectors and the principal investigator filled out the questionnaire. Physicians provided the diagnosis relying on laboratory parameters, physical examination and patient history. The medical staff involved in the management of cases that had undergone the one day training in the near miss questionnaire were questioned by the principal investigator $(\mathrm{JK})$ in case of missing information from patient records to ensure reliability of the data. In the verbal autopsy included in the near miss questionnaire the 23 near miss women themselves provided the principal investigator (JK) statements regarding beliefs surrounding the stillbirth.

\section{Analysis}

The data was entered into SPSS $\AA$ version $21 .{ }^{16}$ Data from the near miss questionnaire regarding the stillbirth near miss and ad mortem women was determined with stillbirth as the dependent variable. ${ }^{16}$ The independent variables were maternal age, level of education, geographical area, gestational age, parity, pregnancy outcome and referral chain (level and place). Simple descriptive statistics were used to present stillbirth, maternal near miss cases and maternal deaths correlating with stillbirth. All data were treated confidentially and patients were identified by codes.

\section{Results}

There were 1,385 births at the tertiary level hospital over the study period of 5months whereof $3.6 \%$ cesarean sections $(n=50)$. Women with severe maternal complications were 138 and out of these $22 \%$ $(n=30)$ had a stillbirth (Figure 1). The women with stillbirth $(n=30)$ were diagnosed with life-threatening condition/s on arrival at the hospital, none of them developed the maternal complication during the hospital stay.

\section{Socio-demographic characteristics}

The mean age for women giving birth to a stillborn was 29years $(\mathrm{SD} \pm 7)$. The majority of the participants had never gone to school; $73 \%(n=22)$ had no formal education. $7 \%(n=2)$ attended primary 
school. Koran and Intermediate schools were attended by $10 \%$ $(\mathrm{n}=3)$ respectively. Only $3 \%(\mathrm{n}=1)$ came from high-income family, $20 \%(n=6)$ came from middle-income families whereas $77 \%(n=23)$ came from low-income families. $90 \%(\mathrm{n}=27)$ resided in rural areas, while $10 \%(n=3)$ resided in urban areas. For socio-demographic characteristics of maternal near miss and maternal deaths for women with stillbirth please see Table 1 .

\section{Causes identified as the life threatening condition among women giving birth to a stillborn and contributing conditions}

The most common severe maternal complication for the 30 women with life threatening conditions were severe obstetric haemorrhage; $50 \%(\mathrm{n}=15)$ : rupture of uterus $(\mathrm{n}=4), \mathrm{APH}(\mathrm{n}=3), \mathrm{PPH}(\mathrm{n}=6)$ and IPH $(\mathrm{n}=2)$ followed by hypertensive disorders in $40 \%(\mathrm{n}=12)$ : eclampsia $(\mathrm{n}=7)$, preeclampsia $(\mathrm{n}=5)$, and pregnancy-related infections $10 \%$ $(n=3)$ : sepsis $(n=1)$, system infections $(n=2)$. The most common contributing condition was anaemia $60 \%(\mathrm{n}=18)$, and prolonged/ obstructed labour before arrival to the referral hospital for $40 \%(n=12)$. The most common severe maternal complication for women with life threating conditions and for women who died when giving birth to a stillborn baby are presented in (Table 2).

\section{Obstetric characteristics}

The leading parity among the women giving birth to a stillborn were $\geq 7$ births for $37 \%(n=11)$ women, followed by the stillborn being the first born baby in $30 \%(\mathrm{n}=9)$. The most common obstetric gestation age for giving birth to a stillborn baby was $37-41$ weeks $57 \%$ $(\mathrm{n}=17)$. Obstetric characteristics for maternal near miss and maternal death women giving birth to a stillborn baby please see Table 3 .

\section{Final mode of delivery}

The most common final mode of delivery for women with life threatening conditions giving birth to a stillborn $(n=30)$ were vaginal delivery for $53 \%(\mathrm{n}=16)$ followed by cesarean section for $43 \%(\mathrm{n}=13)$ women. The cesarean sections were performed within three hours of arrival in the referral hospital. $3 \%(\mathrm{n}=1)$ woman had had a previous cesarean section. For final mode of delivery for women with life threatening conditions and maternal death women giving birth to a stillbirth, please see Table 4 .

\section{Mode of referral}

The leading mode of referral among the 30 women who gave birth to a stillborn baby was self/family-referral for $73 \%(n=22)$ women, followed by $17 \%(n=5)$ women referred by the TBAs to the ANC clinic and $10 \%(\mathrm{n}=3)$ women being referred from the MCHs by the Nurses/Midwives to the referral hospital. Regarding Mode of referral for women with life threatening conditions and maternal death women giving birth to a stillborn, please Table 5 .

\section{Beliefs surrounding stillbirth}

Out of 23 near miss women, 74\% ( $n=17)$ believed holding the stillborn would help them cope with the loss. Religious beliefs would for $91 \%(n=21)$ help them cope faster with the loss. $48 \%(n=11)$ women were aware of the cause of stillbirth and when it occurred. $61 \%(\mathrm{n}=14)$ women believed the womb would be left with diseases which should cause complications in the next pregnancy. $43 \%(\mathrm{n}=10)$ women told that the spouse was well informed about how to support the wife after the loss of the baby. For beliefs surrounding stillbirth, please see Table 6 .

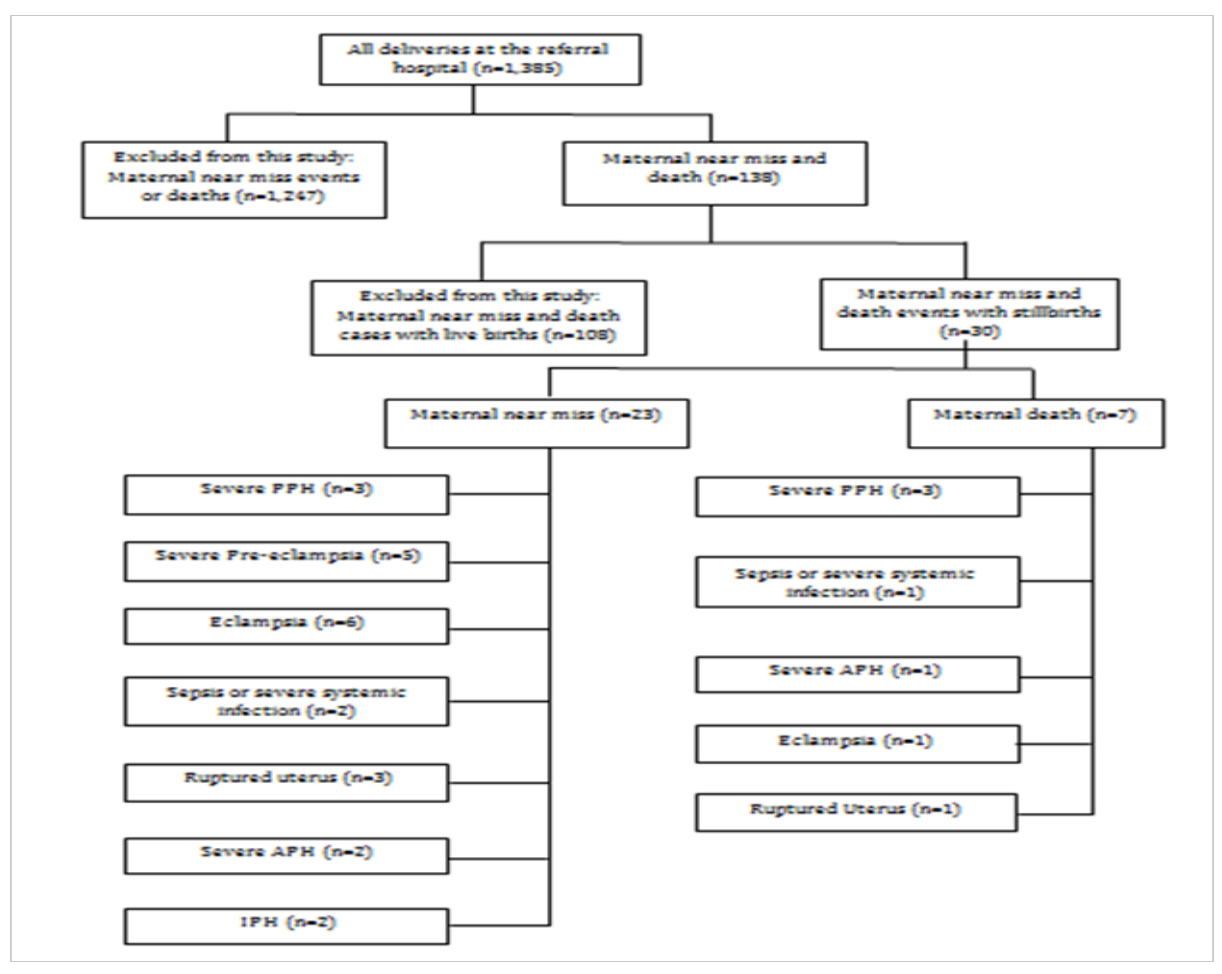

Figure I Flow diagram on inclusion of maternal near miss and deaths among women with stillbirths and the severe maternal complications. 
Table I Socio demographic characteristics of women with severe maternal complications and maternal death for women with stillbirths

\begin{tabular}{|c|c|c|c|c|c|c|}
\hline \multirow{3}{*}{ Characteristics } & \multicolumn{4}{|c|}{ Maternal near miss and death-events $(n=30)$ for women with stillbirth } & & \\
\hline & \multicolumn{2}{|c|}{$\begin{array}{l}\text { Women with life threatening conditions giving } \\
\text { birth to a stillborn baby }\end{array}$} & \multicolumn{2}{|c|}{ Maternal near-miss } & \multicolumn{2}{|c|}{ Maternal death } \\
\hline & \multicolumn{2}{|l|}{$(\mathrm{n}=\mathbf{3 0})$} & \multicolumn{2}{|c|}{$\mathrm{n}=\mathbf{2 3}(\%)$} & \multicolumn{2}{|c|}{$\mathrm{n}=7(\%)$} \\
\hline \multicolumn{7}{|l|}{ Maternal Age } \\
\hline $16-20 \mathrm{yrs}$ & 4 & $13 \%$ & 4 & $17 \%$ & 0 & $0 \%$ \\
\hline $21-25 \mathrm{yrs}$ & 6 & $20 \%$ & 4 & $17 \%$ & 2 & $29 \%$ \\
\hline $26-30 \mathrm{yrs}$ & 7 & $23 \%$ & 5 & $22 \%$ & 1 & $14 \%$ \\
\hline $31-35$ yrs & 8 & $27 \%$ & 6 & $26 \%$ & 2 & $29 \%$ \\
\hline $36-40 \mathrm{yrs}$ & 4 & $13 \%$ & 2 & $9 \%$ & 2 & $29 \%$ \\
\hline$>41 \mathrm{yrs}$ & 1 & $3 \%$ & 2 & $9 \%$ & 0 & $0 \%$ \\
\hline \multicolumn{7}{|l|}{ Level of Education } \\
\hline Never gone to school & 22 & $73 \%$ & 16 & $70 \%$ & 6 & $86 \%$ \\
\hline Koran School & 3 & $10 \%$ & 3 & $13 \%$ & 0 & $0 \%$ \\
\hline Primary School & 2 & $7 \%$ & 1 & $4 \%$ & 1 & $14 \%$ \\
\hline Intermediate School & 3 & $10 \%$ & 3 & $13 \%$ & 0 & $0 \%$ \\
\hline Upper Secondary & 0 & $0 \%$ & 0 & $0 \%$ & 0 & $0 \%$ \\
\hline \multicolumn{7}{|l|}{ School } \\
\hline University & 0 & $0 \%$ & 0 & $0 \%$ & 0 & $0 \%$ \\
\hline \multicolumn{7}{|l|}{ Level of Income } \\
\hline Low level of income & 23 & $77 \%$ & 17 & $74 \%$ & 6 & $86 \%$ \\
\hline Middle level of income & 6 & $20 \%$ & 5 & $22 \%$ & 1 & $14 \%$ \\
\hline High level of income & 1 & $3 \%$ & 1 & $4 \%$ & 0 & $0 \%$ \\
\hline \multicolumn{7}{|l|}{ Residence } \\
\hline Rural area & 27 & $90 \%$ & 20 & $87 \%$ & 7 & $100 \%$ \\
\hline Urban area & 3 & $10 \%$ & 3 & $13 \%$ & 0 & $0 \%$ \\
\hline
\end{tabular}

Table 2 Causes and contributing factors to maternal near miss and death for women giving birth to a stillborn

\begin{tabular}{|c|c|c|c|c|c|c|c|}
\hline \multirow{3}{*}{$\begin{array}{l}\text { Characteristics } \\
\text { Causes identified as the life threatening condition among } \\
\text { women giving birth to a stillborn baby }(\mathrm{n}=30)\end{array}$} & \multicolumn{7}{|c|}{ Maternal near miss-events $(\mathrm{N}=30)$ for women with stillbirth } \\
\hline & \multicolumn{3}{|c|}{$\begin{array}{l}\text { Women with life threatening conditions } \\
\text { giving birth to a stillborn baby }\end{array}$} & \multicolumn{2}{|c|}{$\begin{array}{l}\text { Maternal } \\
\text { near-miss }\end{array}$} & \multicolumn{2}{|c|}{$\begin{array}{l}\text { Maternal } \\
\text { death }\end{array}$} \\
\hline & $(\mathrm{n}=30)$ & & $(\%)$ & $\mathrm{n}=23$ & $(\%)$ & $\mathrm{n}=7$ & $(\%)$ \\
\hline \multirow{4}{*}{ Obstetric hemorrhage } & \multirow{4}{*}{15} & 4 rupture of uterus & \multirow{4}{*}{$50 \%$} & \multirow{4}{*}{10} & \multirow{4}{*}{$43 \%$} & \multirow{4}{*}{5} & \multirow{4}{*}{$7 \%$} \\
\hline & & $3 \mathrm{APH}$ & & & & & \\
\hline & & $6 \mathrm{PPH}$ & & & & & \\
\hline & & $2 \mathrm{IPH}$ & & & & & \\
\hline Hypertensive disorders & 12 & $\begin{array}{l}7 \text { eclampsia } \\
5 \text { pre-eclampsia }\end{array}$ & $40 \%$ & 11 & $4 \%$ & 1 & $1 \%$ \\
\hline Pregnancy-related infection & 3 & $\begin{array}{l}1 \text { sepsis } \\
2 \text { system infection }\end{array}$ & $10 \%$ & 2 & $9 \%$ & 1 & $1 \%$ \\
\hline Contributing/Associated conditions & $(\mathrm{n}=30)$ & & & $\mathrm{n}=23$ & $(\%)$ & $\mathrm{n}=7$ & $(\%)$ \\
\hline Anemia & 18 & & $60 \%$ & 14 & $6 \%$ & 4 & $\%$ \\
\hline Prolonged/obstructed labor & 12 & & $40 \%$ & 9 & $3 \%$ & 3 & $\%$ \\
\hline
\end{tabular}


Table 3 Obstetric characteristics for near miss and maternal death women with life threatening conditions giving birth to a stillborn baby

\begin{tabular}{|c|c|c|c|c|c|c|}
\hline \multirow{3}{*}{ Characteristics } & \multicolumn{6}{|c|}{ Maternal near miss-events $(\mathrm{n}=\mathbf{3 0})$} \\
\hline & \multicolumn{2}{|c|}{ Women with life threatening conditions giving birth to a stillborn baby } & \multicolumn{2}{|c|}{ Maternal near-miss } & \multicolumn{2}{|c|}{ Maternal death } \\
\hline & $(n=30)$ & $(\%)$ & $\mathbf{n}=\mathbf{2 3}$ & $(\%)$ & $\mathbf{n}=7$ & $(\%)$ \\
\hline \multicolumn{7}{|l|}{ Party } \\
\hline 0 & 2 & $7 \%$ & 1 & $4 \%$ & 1 & $14 \%$ \\
\hline 1 & 9 & $30 \%$ & 7 & $30 \%$ & 2 & $29 \%$ \\
\hline 4-Feb & 5 & $17 \%$ & 5 & $22 \%$ & 0 & $0 \%$ \\
\hline 6-May & 3 & $10 \%$ & 2 & $9 \%$ & 1 & $14 \%$ \\
\hline$\geq 7$ & 11 & $37 \%$ & 8 & $35 \%$ & 3 & $43 \%$ \\
\hline \multicolumn{7}{|c|}{ Obstetric Gestation Age } \\
\hline$<24$ weeks & 1 & $3 \%$ & 1 & $4 \%$ & 0 & $0 \%$ \\
\hline 24-27 weeks & 4 & $13 \%$ & 2 & $9 \%$ & 2 & $29 \%$ \\
\hline $28-33$ weeks & 3 & $10 \%$ & 3 & $13 \%$ & 0 & $0 \%$ \\
\hline $34-36$ weeks & 5 & $17 \%$ & 5 & $22 \%$ & 0 & $0 \%$ \\
\hline 37-41 weeks & 17 & $57 \%$ & 12 & $52 \%$ & 5 & $71 \%$ \\
\hline$>41$ weeks & 0 & $0 \%$ & 0 & $0 \%$ & 0 & $0 \%$ \\
\hline
\end{tabular}

Table 4 Final mode of delivery for women with life threatening conditions and maternal death giving birth to a stillborn baby

\begin{tabular}{|c|c|c|c|c|c|c|}
\hline \multirow{3}{*}{$\begin{array}{l}\text { Characteristics } \\
\text { Final mode of delivery }\end{array}$} & \multicolumn{6}{|c|}{ Maternal near miss-events $(\mathrm{n}=\mathbf{3 0})$} \\
\hline & \multicolumn{2}{|c|}{$\begin{array}{l}\text { Women with life threatening conditions giving birth to a } \\
\text { stillborn baby }\end{array}$} & \multicolumn{2}{|c|}{$\begin{array}{l}\text { Maternal near- } \\
\text { miss }\end{array}$} & \multicolumn{2}{|c|}{$\begin{array}{l}\text { Maternal } \\
\text { death }\end{array}$} \\
\hline & $(\mathrm{n}=30)$ & $(\%)$ & $\mathrm{n}=23$ & $(\%)$ & $\mathrm{n}=7$ & $(\%)$ \\
\hline Vaginal delivery & 16 & $53 \%$ & 13 & $57 \%$ & 3 & $43 \%$ \\
\hline Caesarean section & 13 & $43 \%$ & 10 & $43 \%$ & 3 & $43 \%$ \\
\hline $\begin{array}{l}\text { Women died while still } \\
\text { pregnant }\end{array}$ & 1 & $3 \%$ & 0 & $0 \%$ & 1 & $14 \%$ \\
\hline
\end{tabular}

Table 5 Mode of referral for women with life threatening conditions and maternal death giving birth to a stillborn

\begin{tabular}{|c|c|c|c|c|c|c|}
\hline \multirow{3}{*}{$\begin{array}{l}\text { Characteristics } \\
\text { Mode of referral }\end{array}$} & \multicolumn{6}{|c|}{ Maternal near miss-events $(\mathrm{n}=\mathbf{3 0})$} \\
\hline & \multicolumn{2}{|c|}{$\begin{array}{l}\text { Women with life threatening conditions } \\
\text { giving birth to a stillborn baby }\end{array}$} & \multicolumn{2}{|c|}{$\begin{array}{l}\text { Maternal } \\
\text { near-miss }\end{array}$} & \multicolumn{2}{|c|}{$\begin{array}{l}\text { Maternal } \\
\text { death }\end{array}$} \\
\hline & $(\mathrm{n}=30)$ & $(\%)$ & $\mathrm{n}=23$ & $(\%)$ & $\mathrm{n}=7$ & $(\%)$ \\
\hline The TBA sent the woman to an $\mathrm{MCH}$ clinic & 5 & $17 \%$ & 4 & $17 \%$ & 1 & $14 \%$ \\
\hline The TBA referred the woman to hospital & 0 & $0 \%$ & 0 & $0 \%$ & 0 & $0 \%$ \\
\hline Midwives referred the women to hospital & 3 & $10 \%$ & 3 & $13 \%$ & 0 & $0 \%$ \\
\hline $\begin{array}{l}\text { The women and her family without TBA or Midwives } \\
\text { suggestions arrived to the hospital }\end{array}$ & 22 & $73 \%$ & 16 & $70 \%$ & 6 & $86 \%$ \\
\hline
\end{tabular}


Table 6 Beliefs surrounding stillbirth for maternal near miss women with stillbirth

\begin{tabular}{|c|c|c|}
\hline \multirow{2}{*}{ Beliefs Surrounding Stillbirth } & \multicolumn{2}{|c|}{ Maternal Near Miss } \\
\hline & $(n=23)$ & $(\%)$ \\
\hline \multicolumn{3}{|c|}{ Holding the baby born dead helps me cope with the loss } \\
\hline Yes & 17 & $74 \%$ \\
\hline No & 6 & $26 \%$ \\
\hline \multicolumn{3}{|c|}{ Religious belief helps me cope faster with the loss of the baby } \\
\hline Yes & 21 & $91 \%$ \\
\hline No & 2 & $9 \%$ \\
\hline \multicolumn{3}{|c|}{ I was aware about the cause of the stillbirth and when it occurred } \\
\hline Yes & 11 & $48 \%$ \\
\hline No & 12 & $52 \%$ \\
\hline \multicolumn{3}{|c|}{ After a stillbirth the mother beliefs the womb is left with diseases which will cause complications in the next pregnancy } \\
\hline Yes & 14 & $61 \%$ \\
\hline No & 9 & $39 \%$ \\
\hline \multicolumn{3}{|c|}{ My husband was well informed about how to support me after the loss of the baby§ } \\
\hline Yes & 10 & $43 \%$ \\
\hline No & 13 & $57 \%$ \\
\hline
\end{tabular}

\section{Discussion}

The main findings of this pilot using the WHO Near Miss questionnaire $^{13}$ for investigating risk factors for stillbirth focusing the mother-baby dyad ${ }^{11}$ were that over a 5-month period in 2015 , out of 138 women with severe maternal complications arriving to the tertiary level hospital 22\% $(n=30)$ had a stillbirth. Seventy-seven percent $(77 \%)$ of the mothers $(n=23)$ with stillborn babies survived and $23 \%$ died $(n=7)$. They were diagnosed with life threatening conditions on arrival at the hospital and cesarean sections (43\%) was performed within three hours after arrival. None of them developed the maternal complication during the hospital stay. The near miss and death events were caused by obstetric hemorrhage, hypertensive disorders and pregnancy related infections. Underlying causes were anemia and obstructed labor. The women were of low socio-economic status and resident in rural areas. Beliefs regarding the stillbirth for the near miss women were that holding the baby born death helps them cope with the loss $(74 \%)$, religious believes helps them cope faster with the loss $(91 \%)$, Mothers were aware about the cause of stillbirth and when it occurred to $48 \%$, after a stillbirth the mother beliefs the womb is left with diseases which will cause complications in the next pregnancy (61\%), spouses to the maternal near miss woman were well informed about how to support the wife after the loss of the baby to $43 \%$.

Regarding socio-demographic factors, low education level is a well-known risk factor for adverse outcome of a delivery and for stillbirth. ${ }^{6,17}$ Mothers to stillborn babies in this study mostly had no formal education and were hence at risk for adverse outcome of delivery. No formal education can be seen as a risk factor for misbeliefs surrounding stillbirth. One example found in this study was a belief that the womb is left with diseases which will cause complication in the next pregnancy. Resident in rural areas is another well-known risk factor to adverse outcome of pregnancy, ${ }^{6,17}$ also applicable for the women in this study. This can be related to a retrospective study from Uganda ${ }^{17}$ including 4883 delivering women. A detailed review of delivery logs was conducted. In this study from Uganda $430(83.2 \%)$ had been stillborn in the hospital. The conclusion was that the outcome of care provided in tertiary level hospitals depended on what happened before arrival to the tertiary level hospital. This is in line with findings in this study. The woman arrived with the life threatening condition and it was not developed during the hospital stay.

Furthermore, cesarean sections were performed within 3 hours after arrival with the life threatening condition. The authors in the study from Uganda $^{17}$ stated that qualified providers needed to be deployed to rural areas of Uganda to facilitate the prompt identification and early management of pregnancy, delivery, and neonatal complications for women with socio-demographic disadvantages. This might be applicable also in Somaliland setting. In South Africa access to obstetric services was impeded by affordability, availability and acceptability barriers. These were unequally distributed, with differences between socioeconomic groups and geographic areas. Rural women faced the greatest barriers, including longest travel times, highest costs associated with delivery and lowest levels of service acceptability, relative to urban residents. The investigators in South Africa concluded with the following; To move towards achieving its MDGs, more needs to be done to respond to these "patient-oriented" barriers by improving how and where services are provided. The care needs to be provided particularly in rural areas and for poor women, as well as altering the attitudes and actions of health care providers. ${ }^{18}$ This can be related to the situation in Somaliland and to the results of this study. 
The near miss women, their families, TBAs and SBAs might need better information of what causes a stillbirth, how they could prevent it and about the near miss women's beliefs surrounding stillbirth to enable them to communicate this to pregnant women in clinical practice and in that way prevent delay in women's self-referral to the hospital. Particularly anemia and hypertensive disorders can be dealt with during pregnancy at an ANC and complications related to obstructed labor can been dealt with in time when a women is being admitted in an earlier state to the referral hospital. The maternal health literature often suggests that women's health outcomes will be satisfactory if they can access skilled attendance at delivery and emergency obstetric care when pregnancy and delivery complications occur. ${ }^{14}$ In a case study of a near miss case, the vulnerability and maternal mortality in Burkina Faso in was illuminated. The authors challenged the readers with a broader view of the situation for a particular woman and entitled the research "Too poor to live?". ${ }^{19}$

Relating this to contributing obstetric and underlying factors, the concept of a progressive accumulation of problems that ultimately resulted in maternal death, stillbirth or neonatal death and in turn increased the ill-health and economic vulnerability of the family. ${ }^{19}$ In this study, the women giving birth to stillborn babies were not particularly the young ones. It was primipara and multipara women. In line with the study from Burkina Faso ${ }^{19}$ the near miss and death cases with stillborn babies detected in this study seemed "Too poor to live". Young women and women with many children have previously been identified at risk. ${ }^{6,17}$ Haemorrhage, hypertensive disorders and infections were risk factors for stillbirth in this study. The most common contributing condition was anaemia and prolonged/obstructed labour before arrival to the tertiary level hospital. The obstetric risk factors in this study are similar to the study from Uganda ${ }^{17}$ where grand multipara, hypertension, eclampsia, and hemorrhage were detected in 4883 deliveries of which 430 were stillborn. In Somaliland as in the Uganda setting qualified providers need to be deployed to rural areas to facilitate identification and management of pregnancy, delivery and referral to tertiary level hospitals in time to save lives. Further studies are needed in Somaliland to detect underlying causes such as malaria, syphilis and HIV that may plays a role in the development of hypertensive disorders and hemorrhage disorders. ${ }^{20,21}$ Nationwide coverage and utilization of ANC and a functioning referral system to the tertiary level hospital in Somaliland would most likely save lives in line with findings from other African studies. ${ }^{6,8-10,17-19}$

Regarding referral, the families had brought the woman to the referral hospital bypassing the ANC, in this study. Some did not bypass the ANC but they did not get referred to the tertiary level hospital, so the families brought them, and the question arise of how the health system can deliver appropriate care at the right level. ${ }^{22}$ Other studies claim mistrust and misinterpretation in the society of the goal for the state health care system ${ }^{22,23}$ might result in women approaching tertiary level hospitals in a very critical stat. In a study from South Africa ${ }^{18}$ the frustration of health care providers has been described as negative provider-patient interactions. One can conclude here that skilled health-care professionals needs to be well supported by a functional heath system. ${ }^{24}$ What we know from this study is that women/families arrive to the tertiary level hospital in critical conditions. The fact that the women in this study to less than $50 \%$ are aware of the cause of stillbirth and when it occurred and information to the spouse about how to support he wife after the loss in combination with 74\% stating they believe holding the stillborn would help them cope with the loss might provide the reader with a question nark regarding potential communication/lack of communication between care providers and the near miss women in this study.

A mother baby dyad approach to stillbirth prevention and response has been stated to be important, as a healthy mother and baby are the markers of successful management of pregnancy, labor, and childbirth within a state health care system. ${ }^{2}$ Stillbirth prevention and response cannot "stand-alone" and need an integrated programmatic approach from aid and development and politicians..$^{20,21}$ Regarding beliefs related to stillbirth, women with socio-demographic disadvantages in this study had no schooling. How can they be reached with information and knowledge about stillbirth and the advantage of ANC? What is quality care for this most vulnerable group of women in risk of getting stillborn babies and even to become a near miss case and die themselves? The Lancet series are providing a tool for provision of maternity care for all women and children, ${ }^{25}$ however, there are no easy solutions. According to estimates in 2015, there were 303,000 maternal deaths worldwide and 2.6million stillbirths ${ }^{5}$ and most of them occur in low resource settings. In a case study from 2012, the authors challenged the assumption that a functioning health system only will make satisfactory solution.

The authors highlight that vulnerability in health involves a variety of dimensions of deprivation and disadvantage relating to the precariousness of work, income and gender, as well as exclusion from effective social security systems and interactions with weak health systems. The authors conclude aid and development and politicians must move beyond the health sector to address the social and economic determinants of health, to ensure that no woman/family or baby becomes "to poor to live". ${ }^{19}$ In the present study we have shed light on 30 stillborn and their mothers, a dyad who were somehow to disadvantaged socio-demographical vise, health vise, and right vise "to live". We conclude in agreement with the authors to the Lancet series on stillbirth that stillbirth is an unfinished business ${ }^{9}$ particularly in low-resource settings. In this study is it is clear that women want to hold the stillborn, their belief helps them cope with the loss, they need to get rid of misbelieves, they and their family/spouse need information of what happened to the stillborn baby. These findings are in line with a newly duplicated phenomenological study from Somaliland. ${ }^{26}$

\section{Limitations of the study}

There are a couple of limitations in this study. ${ }^{16}$ First, it is a pilot near miss study in a tertiary hospital with no nationwide coverage. Second, it is only 30 near miss and maternal death women with stillborn babies included. Hence, the results should be generalized with caution. Despite the fact that this was a small single-center and hospital-based study it provides a picture of a sad situation regarding stillbirth. Each mother-infant dyad in this pilot is a tragedy, and therefore in its minor contribution this study communicate an important topic that is relevant and interesting to scale up. Regarding beliefs surrounding stillbirth the topic would benefit from a more comprehensive presentation and discussion in a separate study other than the questionnaire piloted here.

\section{Conclusion}

The study highlight the situation for women with socio-demographic disadvantages. Women with low sexual and reproductive health and rights, uneducated and living in rural areas are the most vulnerable. Stillbirth is strongly linked to a vulnerable mother-baby dyad. Risk 
factors for stillbirth in this study, when taking the maternal-baby dyad in consideration, are preventable in Somaliland.

\section{Clinical implications}

Utilization of ANC services, a functioning referral system and education to girls and women regarding beliefs surrounding stillbirth seems especially important for women with socio-demographic disadvantages to prevent stillbirth in Somaliland. This pilot study suggest that the "Near Miss Questionnaire" could be used in low-and middle income settings to detect a full picture of the situation with stillbirth in a country.

\section{Acknowledgements}

None.

\section{Conflict of interest}

The author declares no conflict of interest.

\section{References}

1. HoHP. Republic of Somaliland Annual Report Somaliland. Somalia; 2014

2. Maternal mortality ratio. Swizterland: The World Bank; 2015.

3. Child Mortality Ratio. Switzerland: The World Bank; 2016

4. MOHP. Republic Of Somaliland Annual Report Hargeisa. Somaliland 2015

5. Lawn JE, Blencowe H, Waiswa P, et al. Stillbirths: rates, risk factors, and acceleration towards 2030. Lancet. 2016;387(10018):587-603.

6. Gardosi J, Madurasinghe V, Williams M, et al. Maternal and fetal risk factors for stillbirth: population based study. BMJ. 2013;346:f108.

7. Roos N, Ritter von Xylander R. Why do maternal and newborn deaths continue to occur? Best Pract Res Clin Obstet Gynaecol. 2016;36:30-44.

8. Lawn JE, Blencowe H, Pattinson R, et al. Stillbirths: Where? When? Why? How to make the data count? Lancet. 2011;377(9775):1448-1463.

9. Froen JF, Friberg IK, Lawn JE, et al. Stillbirths: progress and unfinished business. Lancet. 2016;387(10018):574-586.

10. Beauclair R, Petro G, Myer L. The association between timing of initiation of antenatal care and stillbirths: a retrospective cohort study of pregnant women in Cape Town, South Africa. BMC Pregnancy Childbirth. 2014;14:204-213.

11. Starrs AM. Survival convergence: bringing maternal and newborn health together for 2015 and beyond. Lancet. 2014;384(9939):211-213.
12. De Bernis L, Kinney MV, Stones W, et al. Stillbirths: ending preventable deaths by 2030. Lancet. 2016;387(10019):703-716.

13. Near-Miss and quality of care tool. UK: London School of Hygiene and Tropical Medicine; 2014. p. 1-15.

14. Evaluating the quality of care for severe pregnancy complications. The WHO near-miss approach for maternal health. WHO Library Cataloguingin-Publication Data, Switzerland: WHO; 2011.

15. Say L, Souza JP, Pattinson RC. Maternal near miss--towards a standard tool for monitoring quality of maternal health care. Best Pract Res Clin Obstet Gynaecol. 2009;23(3):287-296.

16. Polit D, Beck C. Nursing Research Generating and Assessing Evidence for Nursing Practice. 10th ed. USA: Lippincott Williams \& Wilkins; 2012. p. $1-814$.

17. Moyer CA, Kolars CK, Oppong SA, et al. Predictors of stillbirths and neonatal deaths in rural western Uganda. Int J Gynaecol Obstet. 2016;134(2):190-193.

18. Silal S, Penn-Kekana L, Harris B, et al. Exploring inequalities in access to and use of maternal health services in South Africa. BMC Health Serv Res. 2012;12:120-129.

19. Storeng KT, Drabo S, Filippi V. Too poor to live? A case study of vulnerability and maternal mortality in Burkina Faso. Glob Health Promot. 2013;20(1):33-38.

20. Easterly W, Freschi L. National, regional, and worldwide estimates of stillbirth rates. Lancet. 2011;378(9794):873

21. Cousens S, Blencowe $\mathrm{H}$, Stanton $\mathrm{C}$, et al. National, regional, and worldwide estimates of stillbirth rates in 2009 with trends since 1995: a systematic analysis. Lancet. 2011;377(9774):1319-1330.

22. Pattinson R, Kerber K, Buchmann E, et al. Stillbirths: how can health systems deliver for mothers and babies? Lancet. 2011;377(9777):1610 1623.

23. Byrom S, Downe S. The roar behind the silence: why kindness, compassion and respect matter in maternity care. UK: Pinter \& Martin Ltd; 2015. p. $1-256$.

24. Ten Hoope-Bender P, De Bernis L, Campbell J, et al. Improvement of maternal and newborn health through midwifery. Lancet. 2014:384(9949):1226-1235.

25. Renfrew MJ, McFadden A, Bastos $\mathrm{MH}$, et al. Midwifery and quality care: findings from a new evidence-informed framework for maternal and newborn care. Lancet. 2014;384(9948):1129-1145.

26. Mohamoud Osman H, Ali Egal J, Kiruja J, et al. Womens experiences of stillbirth in Somaliland: A phenomenological description. Sexual and Reproductive Healthcare. 2017;11:107-111. 